American J. of Engineering and Applied Sciences 3 (1): 144-151, 2010

ISSN 1941-7020

(C) 2010 Science Publications

\title{
A Dynamic Voltage Restorer for Voltage Sag Mitigation in a Refinery with Induction Motors Loads
}

\author{
${ }^{1}$ Tarek I. El-Shennawy, ${ }^{2}$ Abdel-Mon'em Moussa, ${ }^{2}$ Mahmoud A. El-Gammal and ${ }^{2}$ Amr Y. Abou-Ghazala \\ ${ }^{1}$ Department of Electrical Engineering, Alexandria National Refining and Petrochemical Co. (ANRPC), \\ El-Sad El-Aaly St., Zip Code: 23111, Wady El-Kamar, El-Max, Alexandria, Egypt \\ ${ }^{2}$ Department of Electrical Power Engineering, Faculty of Engineering, \\ Alexandria University, Alexandria, Egypt
}

\begin{abstract}
Problem statement: ANRPC is a refinery based in Alexandria, Egypt. The plant was subjected to several shutdowns due to tripping of large induction motors, either by under voltage or by over current relays, sometimes by the mechanical protection. The main cause for such unplanned shutdowns was voltage sags. The Dynamic Voltage Restorer (DVR) has recently been introduced to protect the industrial facilities from voltage sags and other voltage disturbances. Existing configurations and control techniques for the DVR aim at protecting industries of high-tech, loads with adjustable speed drives and other power-electronic based loads. Industries with induction motors loads require a complete different approach for the design and control of a suitable DVR. Owing to the inherit inertia of the induction motors and their capability to withstand short-duration, shallow sags, in addition to its tolerance to phase jumps, a DVR with low cost, fast response and simple controller could be configured to fulfill the voltage restoration requirements. Approach: In this study, a simple DVR was proposed, which utilized the classical Fourier Transform (FT) for sag detection and quantification, a controller based on feed-foreword technique which utilized the error signal (difference between the reference voltage and actual measured voltage) to trigger the switches of an inverter using a Pulse Width Modulation (PWM) scheme. The proposed DVR utilized energy from other available feeder or from energy storage unit through a rectifier. Modeling and simulation of the proposed DVR was implemented in the Matlab/Simulink workspace. Results: Simulation results showed that the proposed DVR was efficient in mitigating balanced, unbalanced, multistage and consecutive sags, as well as swells (over-voltages). The main shortcoming of the DVR, being a series device, is its inability to mitigate complete interruptions. Conclusion: The DVR should be configured with respect to the load requirements. With respect to induction motors loads with inherit inertia and insensitivity to phase jumps, the proposed DVR would be of lower cost, simpler controller and faster response.
\end{abstract}

Key words: Power quality, voltage sag, Dynamic Voltage Restorer (DVR), custom power

\section{INTRODUCTION}

Problem statement: Alexandria National Refining and Petrochemicals Co. (ANRPC) is a refinery based in Alexandria, Egypt, with the purpose of producing lead-free, high-octane gasoline. With an average load of $10 \mathrm{MW}$, the plant suffers from several shutdowns due to voltage sags. Although lasting for durations in the range of a quarter second to slightly more than one second, these voltage sags cause large Induction Motors (IMs) connected directly to the supply bus to trip, either by undervoltage or by overcurrent relays, sometimes by the mechanical protection. As the motor torque is directly proportional to the square of the supply voltage, a decrease (sag) to $70 \%$ of the rated voltage will cause the motor torque to decrease to $49 \%$, which may not be sufficient for driving the load. To avoid the risk of damage of the motors' shafts during voltage sags, strict protection settings are applied, leading to numerous (sometimes unnecessary) shutdowns.

A previous study on the effects of voltage sags on IMs showed that IMs are insensitive to very short duration sags (and interruptions). IMs were also unaffected by phase angle jumps associated with most of the voltage sags (ElShennawy et al., 2009).

Corresponding Author: Tarek I. El-Shennawy, Department of Electrical Engineering, Alexandria National Refining and Petrochemical Co. (ANRPC), El-Sad El-Aaly St., Zip Code: 23111, Wady El-Kamar, El-Max, Alexandria 
It follows that a DVR with different approach has to be designed and controlled to countermeasure such voltage disturbances.

Voltage sags: The IEEE defines voltage sag as: A decrease to between 0.1 and 0.9 p.u. in rms voltage or current at the power frequency for durations of 0.5 cycle to $1 \mathrm{~min}$. The amplitude of voltage sag is the value of the remaining voltage during the sag (IEEE Std. 1995-2009).

The IEC terminology for voltage sag is dip. The IEC defines voltage dip as: A sudden reduction of the voltage at a point in the electrical system, followed by voltage recovery after a short period, from half a cycle to a few seconds. The amplitude of a voltage dip is defined as the difference between the voltage during the voltage dip and the nominal voltage of the system expressed as a percentage of the nominal voltage (International Electrotechnical Commission, 1990).

Figure 1 shows an rms representation of voltage sag, the sag starts when the voltage decreases to lower than the threshold voltage $\mathrm{V}_{\text {thr }}(0.9$ p.u. $)$ at time $\mathrm{T}_{1}$. The sag continues till $\mathrm{T}_{2}$ at which the voltage recovers to a value over the threshold value. The duration of the voltage sag is $\left(\mathrm{T}_{2}-\mathrm{T}_{1}\right)$ and the magnitude of the voltage sag is a sag to $\mathrm{V}_{\text {sag }}$ (Won et al., 2005).

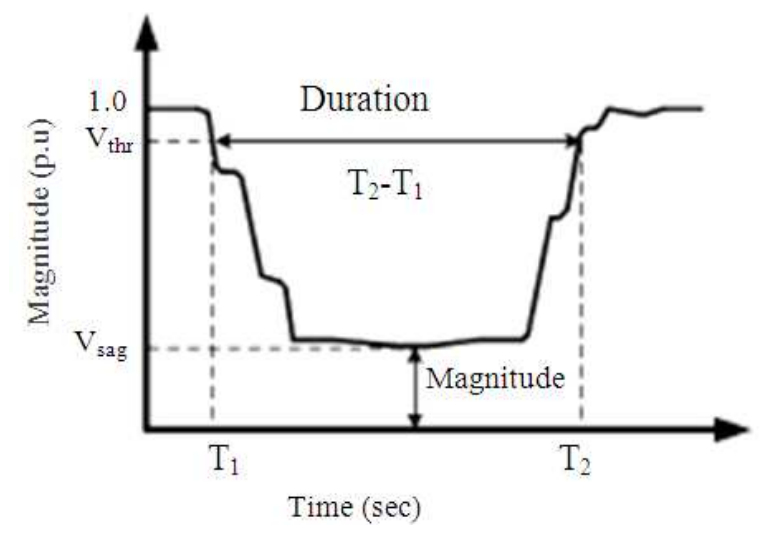

Fig. 1: Voltage sag

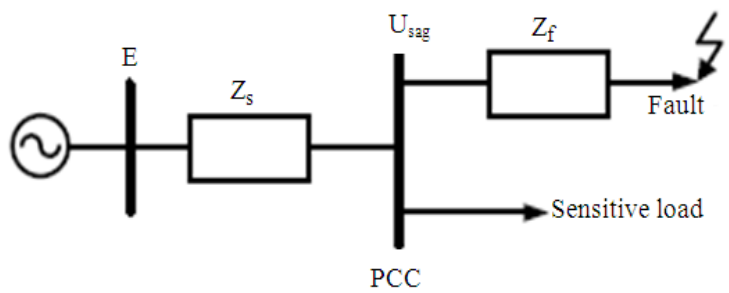

Fig. 2: Faults on parallel feeder causing voltage sag
The principal cause of all voltage sags is a short duration increase in current, mainly due to faults as shown in Fig. 2. Large motor starting and transformer energizing can also result in shallow sags (Bollen, 1999).

To calculate the sag magnitude at the Point of Common Coupling (PCC) in radial systems (which is the case in industrial distribution networks), it is familiar to use the voltage divider model, shown in Fig. 2, where the voltage magnitude at the PCC is given by:

$\mathrm{U}_{\mathrm{sag}}=\frac{\mathrm{Z}_{\mathrm{f}}}{\mathrm{Z}_{\mathrm{s}}+\mathrm{Z}_{\mathrm{s}}} \mathrm{E}$

Where:

$\mathrm{Z}_{\mathrm{s}}=$ The source impedance including the transformer impedance

$\mathrm{Z}_{\mathrm{f}}=$ The impedance between the PCC and the fault including fault and line impedances (Bollen, 1996)

Sag is also associated by a change in voltage phase angle. This change is called phase angle jump (i.e., the phase angle between during sag and pre-sag voltages) and is calculated as the argument of the complex voltage $\mathrm{U}_{\text {sag }}$ (Djokic and Milanovic, 2006).

The Dynamic Voltage Restorer (DVR): The Dynamic Voltage Restorer (DVR), is a device that utilizes solid state (or static) power electronic components and is connected in series to the utility primary distribution circuit. The DVR provides a three phase independently-controlled voltage source, whose voltage vector (magnitude and angle) adds to the source voltage to restore the load voltage to pre-sag conditions (Woodley et al., 1999).

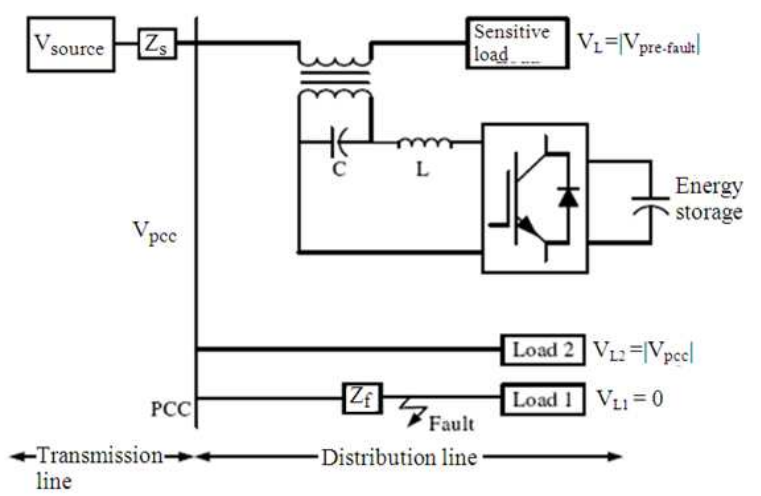

Fig. 3: Dynamic Voltage Restorer (DVR) 
Figure 3 is a simplified circuit for the role and location of the DVR in the distribution system. When a fault occurs on the line feeding Load 1, its voltage collapses to zero. Load 2 experiences a sag equals to the voltage at the PCC and the voltage of sensitive load protected by the DVR is restored to its pre-fault value (Nielsen et al., 2004).

With reference to Fig. 3, the main components of DVR are (Benachaiba and Ferdi, 2009):

Energy storage unit: The required energy for compensation of load voltage during sag can be taken either from an external energy storage unit (batteries) or from the supply line feeder through a rectifier and a capacitor.

Inverter circuit: Since the vast majority of voltage sags seen on utility systems are unbalanced, mostly due to single-phase events, the VSC will often be required to operate with unbalanced switching functions for the three phases and must therefore treat each phase independently. Moreover, a sag on one phase may result in a swell on another phase, so the VSC must be capable of handling both sags and swells simultaneously. The variable output voltage of the inverter is achieved using PWM scheme.

Filter unit: The nonlinear characteristics of semiconductor devices cause distorted waveforms associated with high frequency harmonics at the inverter output. To overcome this problem and provide high quality energy supply, a harmonic filtering unit is used. This can cause voltage drop and phase shift in the fundamental component of the inverter output and has to be accounted for in the compensation voltage.

Series injection transformers: Three single-phase injection transformers are used to inject the missing voltage to the system at the load bus. To integrate the injection transformer correctly into the DVR, the MVA rating, the primary winding voltage and current ratings, the turn-ratio and the short-circuit impedance values of transformers are required. The existence of the transformers allow for the design of the DVR in a lower voltage level, depending upon the stepping up ratio. In such case, the limiting factor will be the ability of the inverter switches to withstand higher currents.

Controller and auxiliary circuits: By-pass switches, breakers, measuring and protection relays are some auxiliaries to the DVR block, in addition to the controller of the DVR.
Compensation (voltage injection) strategy: The most popular voltage injection strategies are pre-sag and inphase compensation methods (Etxeberria-Otadui et al., 2002).

Pre-sag compensation method: The DVR injects the difference (missing) voltage between during-sag and pre-sag voltages to the system, the DVR must compensate for both magnitude and angle, as shown in Fig. 4a. It is the best solution to obtain the same load voltage as the pre-fault voltage and is best suited for loads sensitive to phase angle jumps like ASDs and angle-triggered thyristors-controlled loads.

In-phase voltage injection method: The injected voltage is in phase with supply voltage, as shown in Fig. 4b. The phase angles of the pre-sag and load voltage are different but the magnitude of load voltage is the same as the pre-fault voltage.

A closer look at Fig. 4a shows the following: In normal conditions (pre-sag), the system or supply voltage is equal to the load voltage $\mathrm{V}_{\mathrm{L}}$, both are equal to 1 p.u. with zero angle. During sag, the system voltage decreases to a value of $\mathrm{V}_{\mathrm{s}}$ less than 1 p.u., this reduction in voltage is associated with a phase angle jump $\delta$. The DVR reacts to the sag event and injects a compensating voltage $\mathrm{V}_{\mathrm{dvr}}$ to restore the voltage at the load to pre-sag conditions of both magnitude and angle. The method gives nearly undisturbed load voltage.

The magnitude of the required voltage by the DVR can be calculated as follows:

$\mathrm{V}_{\mathrm{dvr}}=\sqrt{\mathrm{V}_{\mathrm{L}}^{2}+\mathrm{V}_{\mathrm{s}}^{2}-2 \mathrm{~V}_{\mathrm{L}} \mathrm{V}_{\mathrm{s}} \cos \delta}$

Whereas the required phase angle $\theta$ to be compensated can be calculated as follows:

$$
\theta_{\mathrm{drr}}=\tan ^{-1} \frac{\mathrm{V}_{\mathrm{s}} \sin \delta}{\mathrm{V}_{\mathrm{s}} \cos \delta-\mathrm{V}_{\mathrm{L}}}
$$

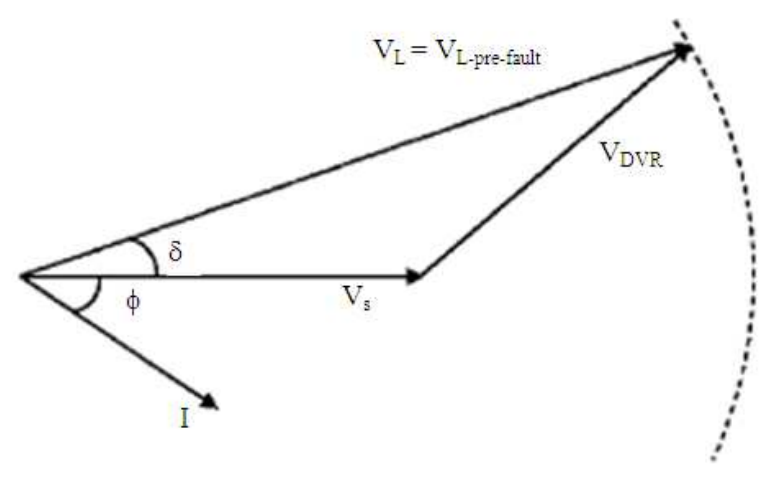

Fig. 4a: Compensation to pre-sag conditions (magnitude and phase) 
In the other strategy, presented in Fig. $4 \mathrm{~b}$, the DVR is designed to compensate the voltage magnitude only. Again, the pre-sag voltage is 1 p.u. with zero angle and during the sag, the system voltage decreases to $V_{L}$ with a phase angle $\delta$. The DVR injects a compensating voltage $\mathrm{V}_{\mathrm{dvr}}$ in phase with the system voltage $\mathrm{V}_{\mathrm{L}}$, to boost the voltage up to the pre-sag voltage magnitude $\mathrm{V}_{\mathrm{s}}$, with no attention to the angle $\delta$. This method is suitable for loads that can withstand phase angle jumps, which is a typical case for induction motor loads which comprise a large portion of the industrial power system, with no sensitive equipment such as ASDs or any equipment depending in its operation on phasetriggered switches.

This method is very simple in implementation, very fast especially in calculating the DVR compensation voltage, which is obviously calculated as:

$\left|\mathrm{V}_{\mathrm{dvr}}\right|=\left|\mathrm{V}_{\mathrm{L}}\right|-\left|\mathrm{V}_{\mathrm{s}}\right|$

And there is no intention for tracking or compensating the phase angle.

\section{Control schemes: The DVR is operated in:}

- Standby mode, where the inverter is not active in the circuit to keep the losses to a minimum

- Active mode, where the DVR senses the sag and reacts as fast as possible to inject the required three phase compensation voltages

- Bypass mode, where the DVR is disconnected and bypassed in case of short circuit occurring inside the facility to protect its sensitive components from excessive short circuit currents (Benachaiba and Ferdi, 2008)

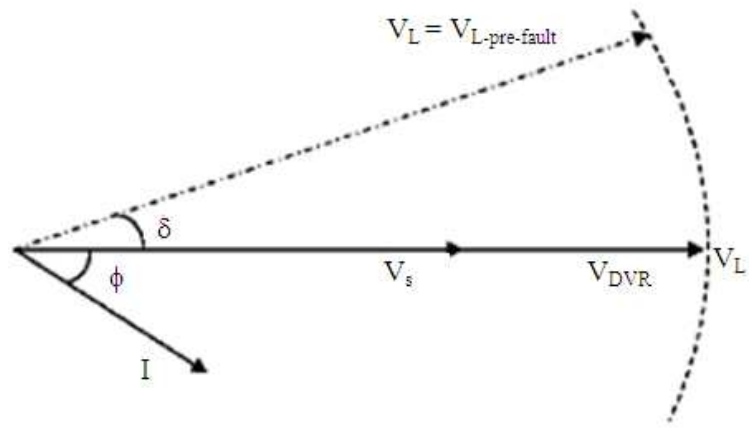

Fig. 4b: In-phase compensation (magnitude compensation only)
Control strategies fall mainly in one of the following two categories:

- Linear control methods comprising the feedback, the feed-foreword and the combined feed controllers

- Non-Linear control methods comprising the Artificial Neural Networks (ANN), the Fuzzy Logic (FL) and the Space Vector (SV) controllers

Although feedback controllers are popular, they require load and source tracking, whereas feedforeword controllers are much simpler yet open-looped, there is no feedback from the load voltage or current (Jing et al., 2008).

\section{MATERIALS AND METHODS}

In this study DVR control strategy based on Inphase compensation strategy was used, as it had proven to be much simpler and hence, the controller and consequently the response time would be faster. A simple feed-foreword controller acquires its voltage values from the source, with no feedback from the load was used, aiming at simple and fast response. Fig. 5 shows the block diagram of the proposed controller for the DVR.

The controller of the proposed DVR consists of the following blocks:

Sag detector: This includes determination of the sag start instant, the depth of the sag, the phase jump angle and the sag end instant. In this study, the FT technique is used. It requires at least one operating cycle to detect the sag start/end events. Other methods in literature include the use of rms values, the use of peak values, the transformation of the three phase voltages to a two dimensional frame ( $\mathrm{dq}$ frame) and therefore to one phasor and the Wavelet Transform (WT) as a multiresolution analysis technique.

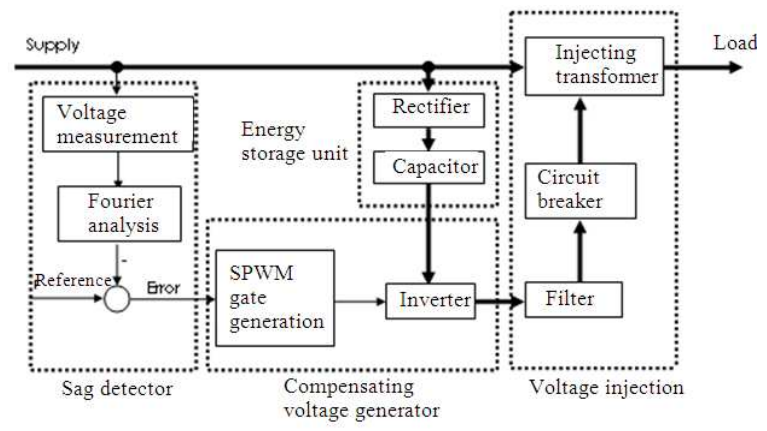

Fig. 5: The block diagram of the proposed controller for the DVR 


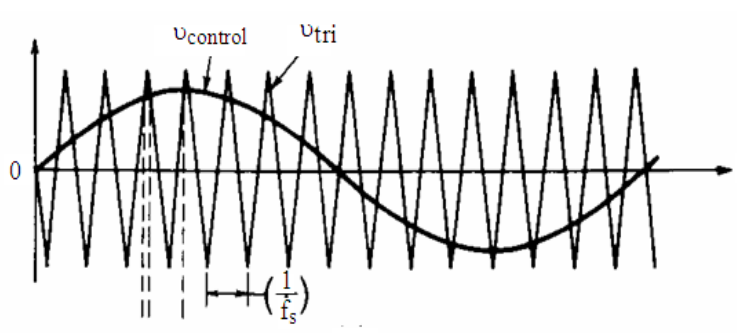

(a)

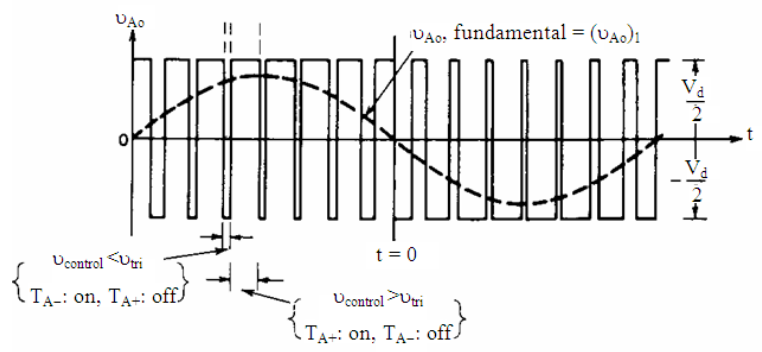

(b)

Fig. 6: Pulse Width Modulation (PWM) scheme

The reference voltage is the supply $11 \mathrm{kV}$ with certain tolerance. The DVR will not operate on small voltage variation events to keep the operational losses to a minimum. In this study, a tolerance of $10 \mathrm{~V}$ is considered. However, this value is very small in practice and it can be increased to $550 \mathrm{~V}$ (5\% of rated voltage).

It is worth mentioning that, the proposed DVR, although does not compensate for the phase angles, yet it tracks them. The sag detector block uses the traditional Fourier Transform (FT) to calculate both the magnitude and angle of the fundamental component of voltage, to make sure that the injected sine wave will be in-phase with the remaining sine wave during the sag event, to have a constructive vector addition of the DVR and the supply voltages.

Computation of the compensating voltage is done using a comparator with one input as the variable system voltage and the other being the fixed reference voltage. The comparison (subtraction) is done for magnitude only, since the compensation strategy used is the In-phase method. The output of the comparator determines the voltage required to be injected by the DVR and is called the error signal. Note that this is done for each phase independently.

Compensating voltage generation: The inverter is the core component of the DVR and its control will directly affect the performance of the DVR. As mentioned earlier, a sinusoidal PWM scheme will be used. The inverter used in this study is a six-pulse inverter, the carrier waveform is a triangular wave with higher frequency. The modulating index will vary according to the input error signal from the comparator.

The basic idea of PWM is to compare a sinusoidal control signal of normal $50 \mathrm{~Hz}$ frequency with a modulating (or carrier) triangular pulses of higher frequency, as shown in Fig. 6. When the control signal is greater than the carrier signal, three switches of the six are turned on and their counter switches are turned off. As the control signal is the error signal, therefore, the output of the inverter will represent the required compensation voltage (Mohan et al., 2002).

In this study, the frequency of the carrier waveform in the PWM was chosen to be $1000 \mathrm{~Hz}$. The thyristors in the inverter circuit are chosen to be of type Integrated Gate Bipolar Transistors (IGBT) for their fast response and robust operation. The dc voltage might be utilized from alternative supply source if available. Otherwise, the line voltage is rectified and the dc energy is stored in large capacitor banks.

Injection of the compensating voltage: Once the error signal magnitude exceeds the tolerance for dynamic voltage variation, the circuit breakers close to connect the DVR into the circuit via the injecting series transformers. Compensation of any drop in the series voltage injection was mainly done to count for the voltage drop and phase shift introduced by the filter and injecting transformers. In this study, the ANRPC load is in the range of $600 \mathrm{~A}$, which will introduce a large voltage drop across the transformer windings and the filter inductance. A $10 \%$ over-compensation was introduced by the controller to counteract any drops.

Modeling and simulation: The performance of the DVR was evaluated by using the Matlab/Simulink program as a simulation tool (Tumay et al., 2005; Boonchiam and Mithulananthan, 2006; Omar et al., 2009). The DVR is connected in series between a three phase programmable (controllable) voltage source with $11 \mathrm{kV}$ line to line rms voltage, $50 \mathrm{~Hz}$ and a refinery load of active power $\mathrm{p}=10 \mathrm{MW}$ and reactive power $\mathrm{Q}$ = $1 \mathrm{MVAR}$ (with installation of power factor correction capacitors). The Simulink model of the proposed DVR is shown in Fig. 7.

\section{RESULTS AND DISCUSSION}

In all cases, the results will be arranged as follows: (a) the supply voltage, (b) the DVR voltage and (c) the load voltage. The simulation time will be $1 \mathrm{sec}$. Note that the minimum operation time of the DVR is 1 cycle or $20 \mathrm{~m} \mathrm{sec}$. 


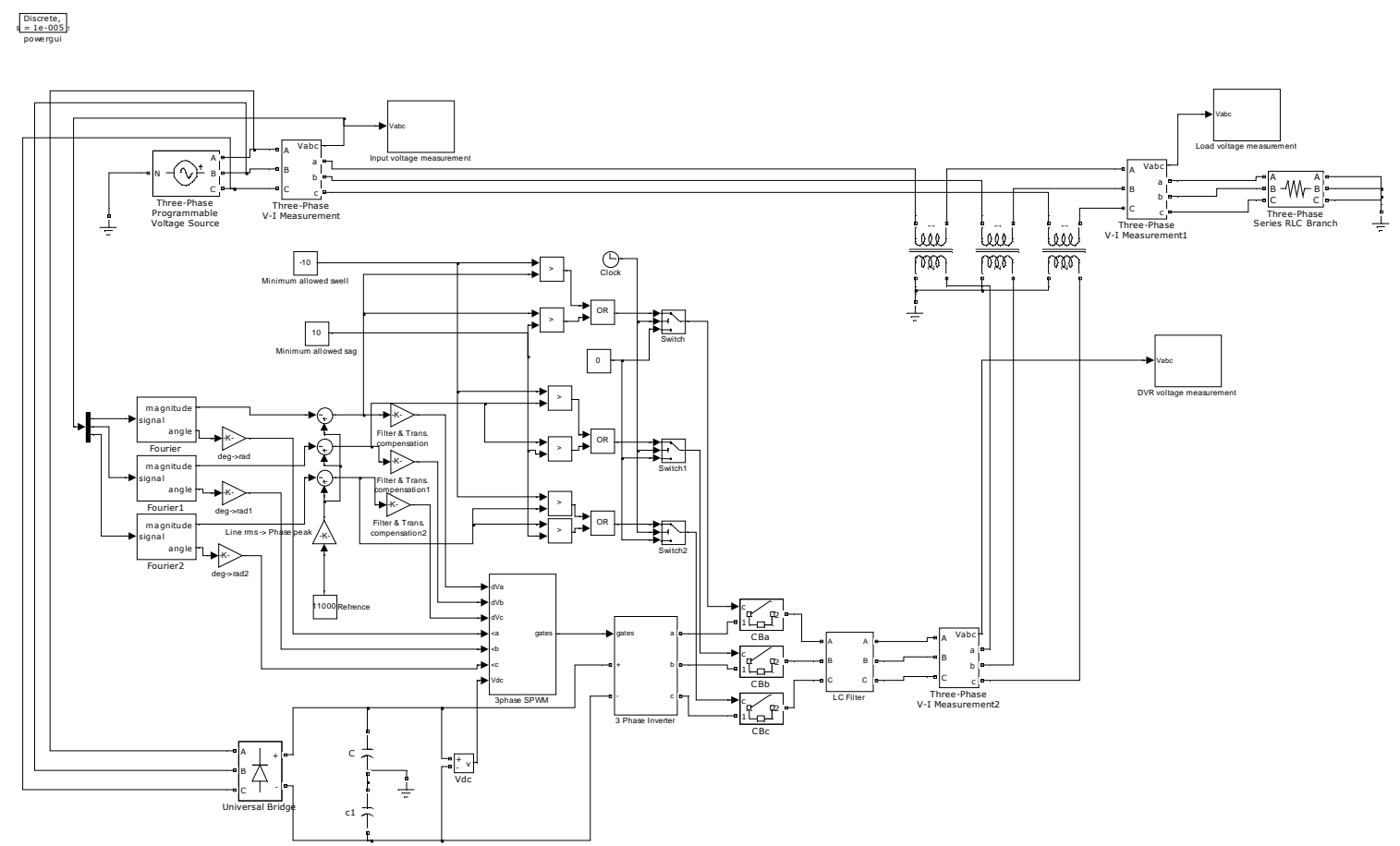

Fig. 7: Simulink model for the proposed DVR using Matlab/Simulink
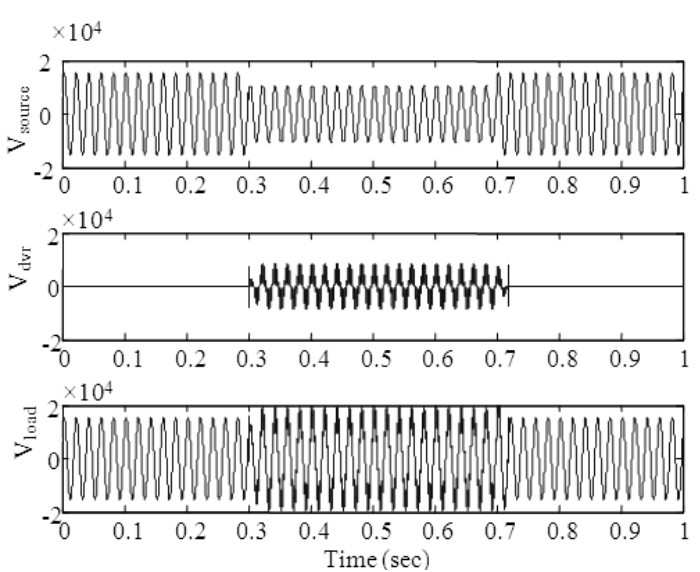

Fig. 8: Three phase balanced voltage sag

Three phase balanced sag: The voltage will be decreased to $70 \%$ of its normal value, for a duration of 0.4 sec from $\mathrm{t}=0.3$ till $\mathrm{t}=0.7$, as shown in Fig. 8, where the line voltage between two phases is shown.

Two consecutive sags: The voltage sags on the three phases to $65 \%$ for $0.15 \mathrm{sec}$ from $\mathrm{t}=0.2$ to $\mathrm{t}=0.35$, followed by voltage recovery to $100 \%$ and then the next sag occurs after $0.3 \mathrm{sec}$ with magnitude of $80 \%$ and lasts for $0.1 \mathrm{sec}$ from $\mathrm{t}=0.65$ till $\mathrm{t}=0.75$, as shown in Fig. 9. Again line voltage between two phases is shown.
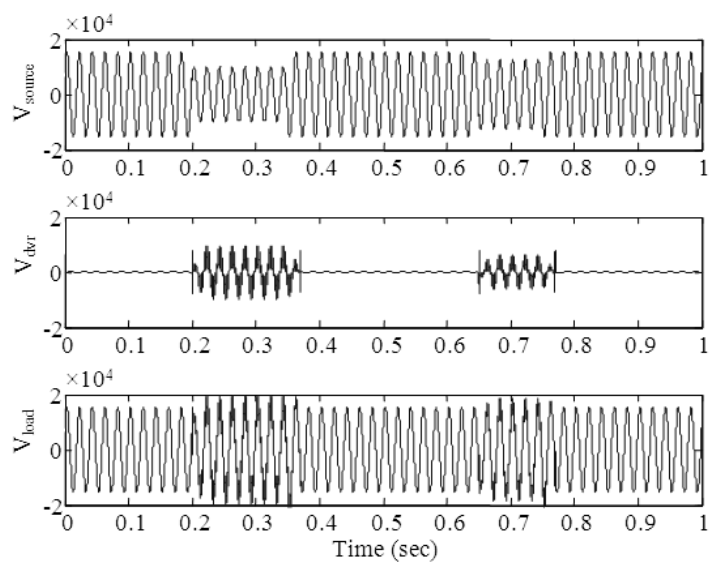

Fig. 9: Consecutive voltage sags

Multi-stage sag: The voltage sags on the three phases to $50 \%$ for $0.2 \mathrm{sec}$ from $\mathrm{t}=0.3$ till $\mathrm{t}=0.5$, after that, the sag prolonged on another stage to $75 \%$ for $0.35 \mathrm{sec}$ from $t=0.5$ till $t=0.85$ as shown in Fig. 10. Once more, line voltage between two phases is shown.

Three phase unbalanced sag: To this category belong the most relevant Single-Line-To-Ground (SLG) faults. Phase A will be sagged to $60 \%$ for $0.5 \mathrm{sec}$ from $\mathrm{t}=0.25$ till $\mathrm{t}=0.75$. Note that the line voltages $\mathrm{Vab}$ and $\mathrm{Vca}$ will be affected, whereas Vbc will not. Figure 11 shows the rms representation of Vab. 

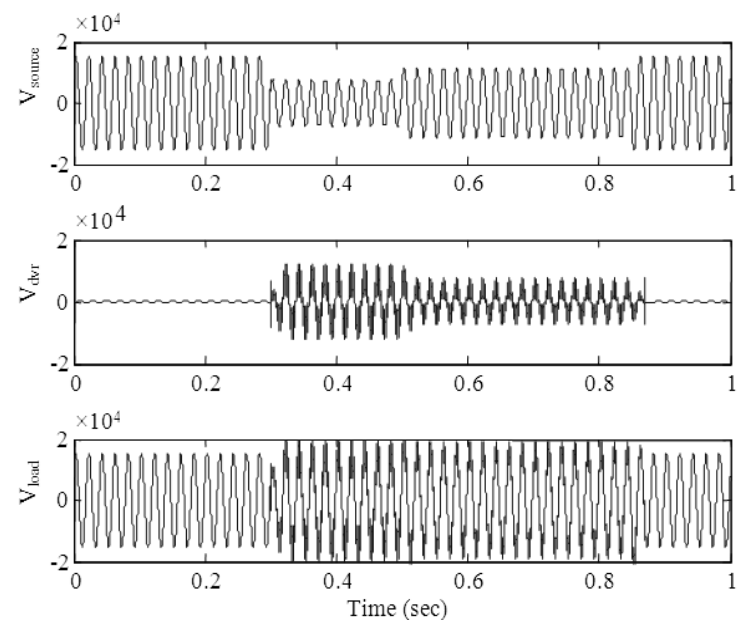

Fig. 10: Multi-stage voltage sags
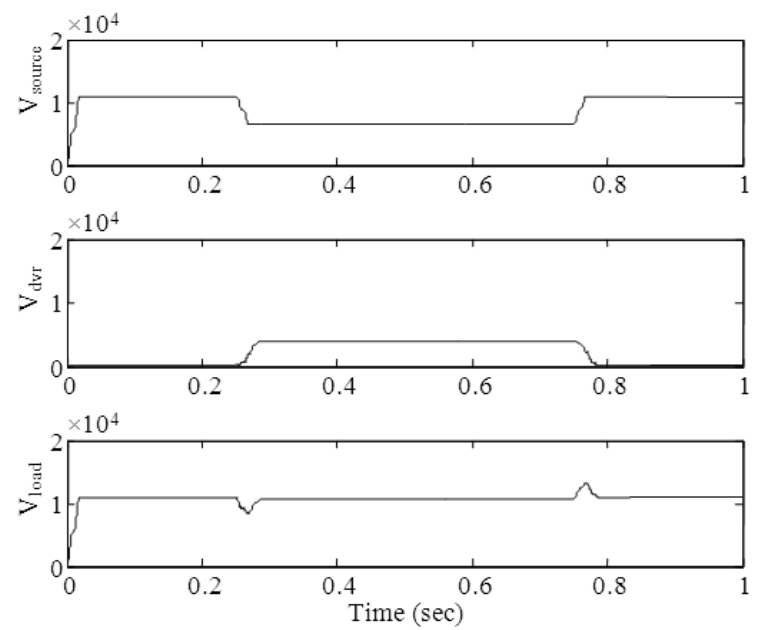

Fig. 11: Single phase voltage sag

Swell: The sudden removal of large loads or application of large capacitor banks may lead to transient voltage rise. This increase in voltage (swell), although not as destructive as sags, may lead to insulation failure of the equipment upon times. The DVR must respond to this disturbance as well. In the simulation, voltage swells to $150 \%$ on the three phases for $0.3 \mathrm{sec}$ from $\mathrm{t}=0.3$ till $\mathrm{t}=0.6$, as shown in Fig. 12. Only the line voltage between two phases is shown.

Interruption: As a series compensator, the DVR must recognize interruptions (complete loss of power on at least one of the three phases, or voltage drop to less than $10 \%$ ) and in this case, the DVR will be bypassed. The interruption lasts for $0.4 \mathrm{sec}$ from $\mathrm{t}=0.3$ till $\mathrm{t}=0.7$, as shown in Fig. 13.
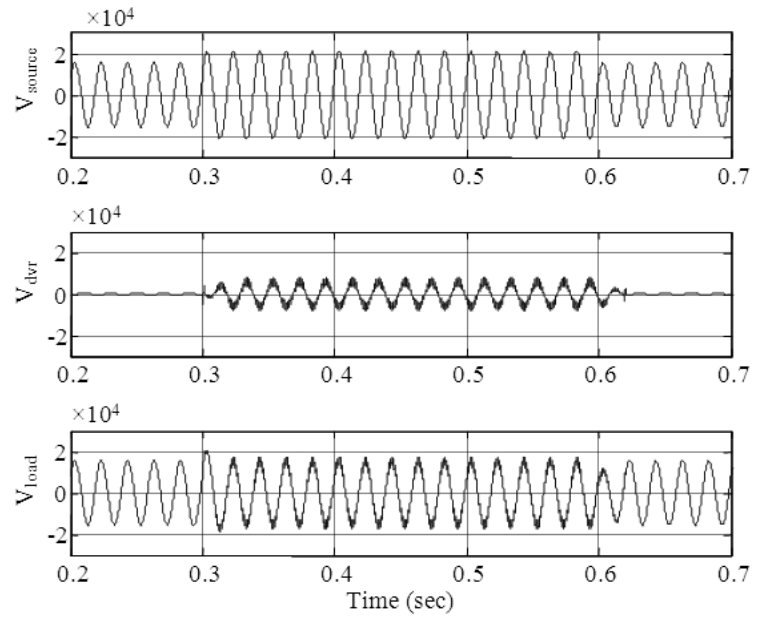

Fig. 12: Voltage swell
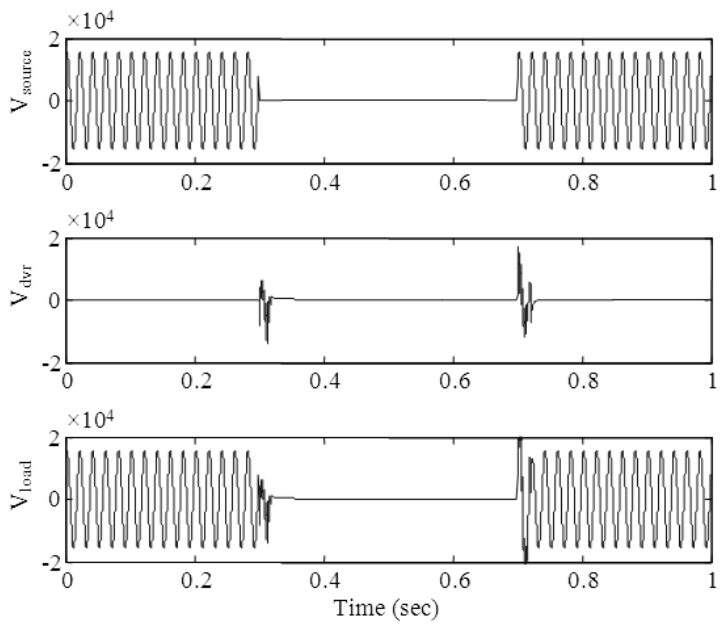

Fig. 13: Three phase interruption

\section{CONCLUSION}

In this study, a simple, fast and cost effective Dynamic Voltage Restorer (DVR) was proposed for mitigating the problem of voltage sags in industrial distribution systems, with a large portion of its load consisting of induction motors. The modeling and simulation of the proposed DVR using Matlab/Simulink had been presented. Detection and quantization of sags was done using the classical Fourier Transform (FT) technique. Calculation of the compensating voltage was done with reference to voltage only, since induction motors are not sensitive to changes in phase angle. A controller based on feed-foreword technique is used which utilizes the error signal (difference between the reference voltage and actual measured voltage) to 
trigger the switches of an inverter using a Pulse Width Modulation (PWM) scheme. The proposed DVR utilizes energy drawn from the supply line source during normal operation and stored in capacitors and which is converted to an adjustable three phase ac voltage suitable for mitigation of voltage sags.

The simulation shows that the DVR performance is satisfactory in mitigating voltage sags/swells. The DVR handles both balanced and unbalanced situations without any difficulties and injects the appropriate voltage component to correct rapidly any deviation in the supply voltage to keep the load voltage constant at the nominal value.

The main advantages of the proposed DVR are simple control, fast response and low cost. Future work will include a comparison with a laboratory experiments on a low voltage DVR in order to compare simulation and experimental results.

Further attention to the filter construction and its parameters selection would be paid in future work. The passive filter is designed to cut off high order harmonics after the inverter circuit and introduce a negligible voltage drop. Other component to be looked for is the injecting transformer. The selection of the transformer parameters and saturation issues require further investigation.

\section{REFERENCES}

Benachaiba, C. and B. Ferdi, 2008. Voltage quality improvement using dynamic voltage restorer. Elect. Power Quality Utiliz. J., 14: 39-46.

Benachaiba, C. and B. Ferdi, 2009. Power quality improvement using dynamic voltage restorer. Am. J. Applied Sci., 6: 396-400.

Bollen, M., 1996. Fast assessment methods for voltage sags in distribution systems. IEEE Trans. Ind. Appli., 32: 1414-1423.

Bollen, M., 1999. Understanding Power Quality Problems: Voltage Sags and Interruptions. 1st Edn., IEEE Press, Piscataway, NJ., ISBN: 13: 9780780347137, pp: 672.

Boonchiam, P. and N. Mithulananthan, 2006. Understanding of dynamic voltage restorers through Matlab simulation. Thammasat Int. J. Sci. Technol., 11: 1-6.

Djokic, S. and J. Milanovic, 2006. Advanced voltage sag characterization. Part I: Phase shift. IEEE Proc. Generat. Transm. Distribut., 153: 423-430. DOI: 10.1049/ip-gtd:20050350
ElShennawy, T., M. El-Gammal and A. Abou-Ghazala, 2009. Voltage sag effects on the process continuity of a refinery with induction motors loads. Am. J. Applied Sci., 6: 1626-1632.

Etxeberria-Otadui, I., U. Viscarret, S. Bacha, M. Caballero and R. Reyero, 2002. Evaluation of different strategies for series voltage sag compensation. Proceeding of the IEEE 33rd Annual Power Electronics Specialists Conference, June 23-27, Cairns, Queensland, Australia, pp: 1797-1802.

IEEE Std. 1995-2009, IEEE recommended practice for monitoring electric power quality. pp: 91 .

International Electrotechnical Commission, 1990. IEC TR 61000-2-1 Electromagnetic Compatibility (EMC)-Part 2: Environment-section 1: Description of the environment. pp: 28.

Jing, W., X. Aiqin and S. Yueyue, 2008. A survey on control strategies of dynamic voltage restorer. Proceeding of the IEEE 13th International Conference Harmonics and Quality of Power (ICHQP), Sept. 28-Oct. I, Wollongong, NSW., pp: 1-5. DOI: 10.1109/ICHQP.2008.4668845

Mohan, N., T.M. Undeland and W.P. Robbins, 2002. Power Electronics: Converters. Applications and Design. 2nd Edn., John Wiley and Sons, ISBN: 978-0-471-22693-2, pp: 824.

Nielsen, J.G., M. Newman, H. Nielsen and F. Blaabjerg, 2004. Control and testing of a dynamic voltage restorer (DVR) at medium voltage level. IEEE Trans. Power Elect., 19: 806-813. DOI: 10.1109/TPEL.2004.826504

Omar, R., N.A. Rahim and M. Sulaiman, 2009. Modeling and simulation for voltage sags/swells mitigation using dynamic voltage restorer. J. Theor. Applied Inform. Technol., 5: 464-470.

Tumay, M., A. Teke, K. Cagatay, M. Bayındır and U. Cuma, 2005. Simulation and modeling of a dynamic voltage restorer. Proceeding of the 4th International Conference Electrical and Electronic Engineering, Dec. 7-11, Turkey, pp: 1-5.

Won, D., S. Ahn and S. Moon, 2005. A modified sag characterization using voltage tolerance curve for power quality diagnosis. IEEE Trans. Power Delivery, 20: 2638-2643. DOI: 10.1109/TPWRD.2005.855626

Woodley, N., R. Morgan and A. Sundaram, 1999. Experience with an inverter-based dynamic voltage restorer. IEEE Trans. Power Delivery, 14: 1181-1185. 